\title{
REFLEKSI PLURALISME MELALUI FILM ANIMASI SI ENTONG SEBAGAI IDENTITAS BUDAYA INDONESIA
}

\author{
Meta Sya ${ }^{1}$, Rustono Farady Marta ${ }^{2}$, Ido Prijana $\mathrm{Hadi}^{3}$ \\ 1,2 Magister Ilmu Komunikasi, Universitas Bunda Mulia, Jln. Lodan Raya No.02, Jakarta Utara 14430 \\ ${ }^{3}$ Fakultas Ilmu Komunikasi, Universitas Kristen Petra, Jln. Siwalankerto No.121-131, Surabaya 60236 \\ Email: meta_sya@yahoo.com
}

Diterima : 10 Desember 2019

Disetujui : 07 Januari 2020

Diterbitkan : 20 Februari 2020

\begin{abstract}
Abstrak
Indonesia dikenal memiliki banyak kekayaan budaya yang beraneka ragam. Keberagaman ini dipersatukan melalui semboyan bangsa Indonesia, yaitu Bhinneka Tunggal Ika. Selanjutnya, semboyan ini harus terus dipertahankan dengan cara memperkenalkannya kepada anak-anak sejak usia dini. Pemanfaatan teknologi bisa dilakukan dalam memperkenalkan semboyan tersebut, yaitu melalui animasi film anak- anak. Salah satu hasil karya bangsa yang merefleksikan pluralisme dan menampilkan identitas budaya, yaitu Si Entong. Keunikan yang ditampilkan dalam Si Entong adalah karakter anak-anak yang berasal dari berbagai macam suku dan penggunaan logat bahasa. Bersandar pada teori negosiasi identitas yang dikemukakan oleh Stella Ting-Toomey, maka hasil temuan penulis pada film animasi Si Entong tersebut dielaborasi dengan metode analisis konten kualitatif Phillip Mayring. Penelitian ini berpijak pada paradigma interpretif untuk menemukan tiga elemen utama analisis konten, antara lain: abstraksi, eksplikasi, dan strukturasi. Ketiga tahapan ini diidentifikasi penulis sebagai refleksi nilai pluralisme sebagai identitas budaya Bangsa Indonesia yang tertuang dalam cerita "Si Entong".
\end{abstract}

Kata Kunci: Film Animasi Si Entong; Pluralisme; Teori Negosiasi Identitas

\begin{abstract}
Indonesia is known as a country full of diversity, and it is united through the motto of the Indonesian people, namely "Bhinneka Tunggal Ika". However, this motto must be maintained by introducing it to children from an early age. The use of technology can be utilized to introduce the motto through children's film animation. One of the Indonesian works who reflects the spirit of pluralism and displays cultural identity, namely Si Entong. The uniqueness shown in the Entong movie is the character of children who come from various ethnic groups and the use of dialect. Relying on the theory of identity negotiation was proposed by Stella Ting-Toomey, the authors' findings in the animated film "Si Entong" were elaborated with Phillip Mayring's qualitative content analysis method. This research rests on an interpretive paradigm to find three main elements of content analysis, including: abstraction, application and structuration. These three stages are identified by the researcher as a reflection of pluralism and cultural identity in the story of "Si Entong".
\end{abstract}

Keywords: Identity Negotiation Theory; Pluralism; Si Entong Animated Film 


\section{PENDAHULUAN}

Bangsa Indonesia dikenal sebagai bangsa yang berbhineka, yaitu bangsa yang majemuk dan pluralitas, terdiri dari suku, etnis, agama, adat istiadat. Kemajemukan ini dipersatukan dengan semboyan bangsa Indonesia, yaitu Bhinneka Tunggal Ika, yang berarti walaupun berbeda tetapi tetap satu jua (Marta, 2017:1). Bhinneka Tunggal Ika menjadi suatu kalimat pemersatu yang sangat penting agar masyarakat Indonesia menjadi masyarakat utuh yang tidak mudah terpecah belah. Akan tetapi, mempersatukan keberagaman yang ada bukanlah hal yang mudah karena konflik ataupun pertentangan bisa muncul kapan saja. Octaviani (2013:4) mengutip dari Kumbara (2009) mengungkapkan pluralitas budaya ini, di satu sisi menjadi kekayaan bangsa yang tidak ternilai, di sisi lain mengandung potensi konflik yang bisa menimbulkan disintegrasi bangsa. Boer \& Lesmana (2018:52) memaparkan di era globalisasi yang terus berkembang, identitas budaya Indonesia seakan mulai memudar karena banyaknya generasi sekarang lebih senang mengadopsi budaya dari luar dan menganggap kebudayaan lokal sebagai sesuatu yang dianggap ketinggalan zaman sehingga, mereka menjadi generasi yang lebih memahami budaya luar daripada memahami negeri sendiri. Nahak (2019:3) menjelaskan dilihat dari kenyataannya, masyarakat Indonesia saat ini lebih memilih kebudayaan asing yang dianggap lebih menarik dan praktis. Kebudayaan lokal banyak yang luntur akibat dari kurangnya generasi penerus yang memiliki minat untuk belajar dan mewarisinya. Suryandari (2017:2) juga mengungkapkan hal yang sama bahwa di tengah budaya global seperti saat ini, semua aspek kehidupan seperti dipaksa agar dapat mengikuti standar yang bersifat global, mulai dari barang, jasa, dan gaya hidup (life style).

Seiring berkembangnya kemajuan teknologi, Indonesia mau tidak mau harus dapat beradaptasi (Kristiyono \& Sirikit, 2019:160). Maksudnya disini adalah memanfaatkan teknologi yang ada dalam memperkenakan semangat Bhinneka Tunggal Ika kepada generasi penerus. Basseng, dkk (2019: 80) menjelaskan bahwa sosialisasi secara terus-menerus perlu dilakukan dari masa ke masa dalam menjaga kelestarian semboyan Bhinneka Tunggal Ika yang diintepretasikan dalam perbuatan seluruh rakyat Indonesia. Jika hal tersebut tidak dilakukan, persatuan dalam keberagaman yang sudah dibangun sejak negara ini berdiri akan mudah terkikis. Salah satunya adalah pemanfaatan film animasi bagi anak-anak. Arsita, dkk (2014:5) memberikan penjelasan bahwa dewasa ini animasi atau film kartun Jepang cukup berkembang pesat dan cukup menjamur di berbagai stasiun televisi di Indonesia sehingga semakin banyak pula kesempatan anak-anak mencari film yang menarik yang berasal dari berbagai berlahan dunia. Sundari, dkk (2017:2) menegaskan bahwa setiap cerita rakyat yang dikisahkan mewakili identitas budaya dan kepribadian bangsa Indonesia akan tetapi, cerita rakyat mulai kehilangan eksistensinya di kalangan anak- anak. Anak-anak lebih tertarik menyaksikan cerita-cerita dari belahan dunia barat. (Haryono, 2017:31) Animasi film anakanak dapat menjadi suatu sarana untuk memperkenalkan identitas budaya Indonesia karena film animasi anak-anak menjadi daya tarik tersendiri bagi mereka. Hdiwidjaja (2017:1) menegaskan bahwa kartun/ animasi yang seringkali ditonton di youtube ataupun televisi menjadi salah satu metode yang dapat digunakan sebagai sarana informasi/edukasi bagi anak-anak karena kartun/animasi dikemas dengan warna - warna yang menarik bagi mereka. 
Salah satu karya anak bangsa, yaitu animasi film Si Entong, yang merefleksikan suatu kehidupan yang pluralisme. Keseharian Si Entong mencerminkan kerukunan hidup meski mereka berbeda satu sama lain. Terlihat dari teman-teman Entong, ada yang dari Papua dan Tionghoa. Selain itu, latar yang digunakan dalam film tersebut menggunakan budaya betawi, dan beberapa istilah yang digunakan, seperti sapaan dalam bahasa betawi. Dalam film si Entong, peneliti memilih dua judul episode yang berbeda, yaitu pada serial TV episode "Maaf Lahir Batin" dan "Ling Long". Alasan pemilihan dua episode ini adalah dalam episode "Maaf Lahir Batin", adanya penyampaian nilai toleransi, yaitu meskipun teman Entong yang merayakan Natal dan Imlek, mereka juga harus merayakan suasana lebaran dengan memberikan bekal rantang kepada mereka. Yanti (2011:9) memaparkan bahwa makna tradisi tukar rantang yang dipercaya oleh masyarakat Kotasepang sebagai cara untuk menjaga jalinan silaturahim di antara keluarga dan saling berbagi antar keluarga atau tetangga (sedekah). Selain itu, penggunaan istilah angpao dalam merayakan lebaran. Kemudian, pada episode "Liang Liong", Entong bersama teman-temannya berlatih memainkan liang liong. Liang Long merupakan suatu pertunjukan atau tarian tradisional dalam kebudayaan masyarakat Tionghoa. Point ini dianggap penting karena kesenian juga dapat menjadi sarana pemersatu antara etnis yang berbeda. Setiawan (2016:6) memberikan pemaparan bahwa kesenian juga berfungsi sebagai pemersatu bangsa, mendorong ke arah lahirnya persahabatan, menggalang kerja sama, dan menghilangkan batas-batas kesukuan dan batas-batas wilayah administrasi pemerintahan. Bahwa batas-batas kesukuan dan batasbatas wilayah administrasi pemerintahan menjadi 'hilang' melalui kesenian dapat kita lihat di kota-kota di mana berbagai etnis tinggal bersama dan menjadi satu.

Peneliti mengambil beberapa penelitian terdahulu dalam melihat kebaruan dalam penelitian ini Pertama, Negosiasi Identitas Sosial Etnis Jawa di Kota Metropolitan: Sebuah Studi Fenomenologi pada masyarakat kampung Jawa (Rohmawati, 2017). Penelitian mengungkapkan bahwa bentuk negosiasi identitas sosial antarwarga yang berlangsung di Kampung Jawa dapat dikategorikan ke dalam lingkup interaksi kegiatan sehari-hari dan interaksi dalam kegiatan rutin yang diadakan oleh musyawarah RT Penelitian kedua, identifikasi nilai kemajemukan Indonesia sebagai identitas bangsa dalam iklan mixagrip ersi keragaman budaya (Marta dan Rieuwpassa, 2018). Penelitian ini secara tidak langsung ingin menghimbau kepada seluruh lapisan masyarakat Indonesia agar dapat menanamkan ajaran "kasih" atau sikap "epoche" dalam melestarikan toleransi dalam masyarakat yang majemuk agar nilai-nilai luhur budaya tidak mati dan hilang begitu saja hanya. Kedua penelitian terdahulu menjelaskan tentang negosiasi identitas yang terjadi di tengah masyarakat yang multikulturalisme dan pengenalan nilai kemajemukan tersebut melalui sebuah iklan. Dalam penelitian ini ingin melihat bagaimana bagaimana proses negosiasi identitas yang disampaikan dalam sebuah film animasi anak-anak sebagai bagian dalam memperkenalkan pluralism kepada anak-anak, yang diharapkan dapat menjadi suatu sarana dalam memperkenalkan semangat Bhinneka Tunggal Ika kepada generasi penerus.

Secara umum, pluralisme dipandang sebagai kesediaan seseorang untuk menerima keberagaman yang ada (Fensi, 2018:144). Adanya sikap untuk saling menghargai dan 
menghormati masyarakat yang berbeda suku, agama, dan budaya. Hamdun (2017:55) mengungkapkan bahwa pluralisme bukan hanya sekedar keadaan atau fakta yang bersifat plural, jamak, atau lebih tapi, pluralism termanifestasi dalam sikap untuk saling menghormati, menghargai, memelihara, dan bahkan mengembangkan atau memperkaya keadaan yang besikap plural, jamak, dan banyak. Hal senada juga diungkapkan dalam Ikmal (2015:6) bahwa pluralisme seharusnya bukan hanya sekedar pluralitas, pluralisme harus mengakomodir dan memahami seluruh keanekaragaman dan kemajemukan nilai-nilai dasar dari pluralisme yaitu nilai kesamaan dan kebersamaan, sikap terbuka dalam menerima perbedaan yang ada (saling memahami), saling menghormati, saling menolong, prinsip kebebasan, keadilan.

Selain itu, Sutarto (2016:6) memberikan pemaparan bahwa perlu dilakukan adanya kegiatan nyata dalam mengakui perbedaan budaya dan pluralisme budaya, yaitu termasuk pelestarian budaya lokal kedaerahan agar dapat mewujudkan integrasi nasionalisme yang mengakui perbedaan budaya lokal. Salah satu contoh fenomena yang mengandung konsep pluralisme dan toleransi beragama adalah yang dikemukakan oleh Mushodiq (2017: 19) bahwa konsep pluralisme dapat dilihat keikutsertaan/andil seluruh penduduk dalam setiap hari besar agama-agama. Setiap penduduk memiliki antusias yang sangat baik dalam mengikuti dan ikut andil dalam acara-acara besar keagamaan, baik acara-acara besar dari agama yang mereka peluk, maupun acara-acara besar dari agama lain

Sikap pluralisme dalam kehidupan masyarakat yang majemuk, tidak terlepas dari aktivitas komunikasi dimana setiap orang berusaha melakukan negosiasi terhadap identitas mereka. Sebagi contoh mengutip dari Santalia (2016: 6) yang mengungkapkan Kelompok minoritas lain yang sering dibela Gusdur adalah penganut Konghucu, kendati negara tidak mengakui keberadaan negara ini khususnya pada masa ode baru tapi Gusdur tetap membelahnya sebagai hak pribadi terhadap suatu keyakinan tentang kebenaran ajaran yang dianut. Yahya dan Rahardjo (2018:3) mengungkapkan bahwa teori negosiasi identitas menurut Stella Ting-Toomey, mengeksplorasi cara-cara di mana identitas dinegosiasi (dibahas) dalam interaksi dengan orang lain, terutama dalam berbagai budaya. Interaksi yang dilakukan setiap individu dalam menegosiasikan identitasnya memiliki beragam cara yang berbeda.

Kemudian, dalam jurnalnya Hidayat (2014:7) Ting Toomey mencetuskan tiga landasan dasar dalam teori negosiasi identitas yaitu: pengetahuan (knowledge) sebagai pemahaman akan pentingnya identitas etnik dan kemampuan melihat apa yang penting bagi orang lain. Sedangkan kesadaran (mindfulness) berarti kesiapan berganti ke perspektif baru. Terakhir, kemampuan (skill), yaitu kemampuan untuk menegoisasi identitas melalui observasi yang teliti, menyimak, empati, kepekaan non verbal, kesopanan dan kolaborasi.

Secara umum teori negosiasi identitas adalah setiap individu akan menegosiasikan identitas ketika sedang menghadapi individu lain yang memiliki nilai identitas berbeda. Teori ini pada akhirnya menjelaskan bahwa komunikasi antar budaya akan dapat berjalan efektif ketika tercapai keberhasilan dalam proses negosiasi identitas tersebut. 


\section{METODOLOGI PENELITIAN}

Penelitian ini dilakukan dengan menggunakan metode analisis kualitatif Philip Mayring dengan paradigma intepretif. Muslim (2016:2) mengkaji bahwa pendekatan intepretif berangkat dari upaya untuk mencari penjelasan tentang peristiwa-peristiwa sosial atau budaya yang didasarkan pada perspektif dan pengalaman orang yang diteliti.

Mayring (2014:64) memaparkan dalam bukunya bahwa ada tiga bentuk prosedur analisis dalam melakukan intepretasi pada penelitian kualitatif, yaitu 1) Ringkasan adalah untuk mengurangi bahan sedemikian rupa sehingga mempertahankan isi yang dianggap penting. 2) Eksplikasi adalah untuk memberikan bahan tambahan tentang komponen teks yang meragukan individu (istilah, kalimat...dengan pandangan untuk meningkatkan pemahaman, menjelaskan, menafsirkan bagian teks tertentu 3) Strukturisasi adalah menyaring aspek tertentu dari sebuah materi yang terstruktur sesuai isi, bentuk, dan skala tertentu.

Mayring mengembangkan model analisis konten kualitatif dan mengemukakan tiga analitis yang berbeda prosedur di mana dapat dilakukan baik secara mandiri atau kombinasi, tergantung pada pertanyaan penelitian tertentu. Kohlbacher (2006:11) memberikan definsi pada ringkasan : bertujuan untuk mengurangi materi dengan cara mempertahankan konten yang penting dan dengan abstraksi. Eksplikasi: berkaitan dengan menjelaskan, mengklarifikasi, dan menambahkan catatan. Strukturisasi: digunakan dalam analisis konten klasik dan juga dipandang sebagai teknik analisis konten yang paling penting, yang tujuannya adalah untuk menyaring struktur tertentu dari materi.

\section{HASIL DAN PEMBAHASAN}

Pesan yang tersaji melalui film animasi Si Entong menjadi perhatian utama dalam menyingkapkan pluralisme yang disajikan dalam audio-visual. Nilai yang ditampilkan berupa interaksi yang diakukan antara anak-anak yang memiliki latar belakang suku yang berbeda dan pengenalan akan kebudayaan betawi bagi anak-anak. Refleksi pluralisme sebagaimana interaksi antara anak-anak yang berbeda suku, agama, dan budaya banyak ditayangkan di dalam sebuah film, salah satunya film animasi anak-anak yang menjadi representasi masyarakat Indonesia yang beranekaragam. Oleh karena itu, peneliti akan menganalisa dua episode dengan judul yang berbeda, yaitu Si Entong "Maaf Lahir Batin Ya" dan Si Entong "Liang Liong". Kedua episode tersebut dianggap mewakili refleksi pluralism karena adanya sikap menghargai perbedaan terhadap temannya-temannya yang tidak merayakan Imlek dan Natal, serta permainan Liang Liong sebagai sarana pembauran antara etnis Tionghoa dan lainnya.

\section{Episode Si Entong "Maaf Lahir Batin Ya"}

Mengacu pada teori negosiasi identitas yang dikemukakan oleh Stella Ting-Toomey tentang cara-cara dimana identitas dinegosiasi dalam interaksi dengan orang lain yang berasal dari budaya yang berbeda. Perbedaan latar belakang tersebut terjadi dalam ruang lingkup antara anak-anak yang berbeda suku, agama, dan budaya. Berikut adalah analisa 
peneliti terhadap refleksi nilai pluralism yang ditampilkan dalam film Si Entong dengan menggunakan tiga kunci kemampuan lintas budaya, yaitu knowledge (pengetahuan), mindfulness (kesadaran), skill (kemampuan)

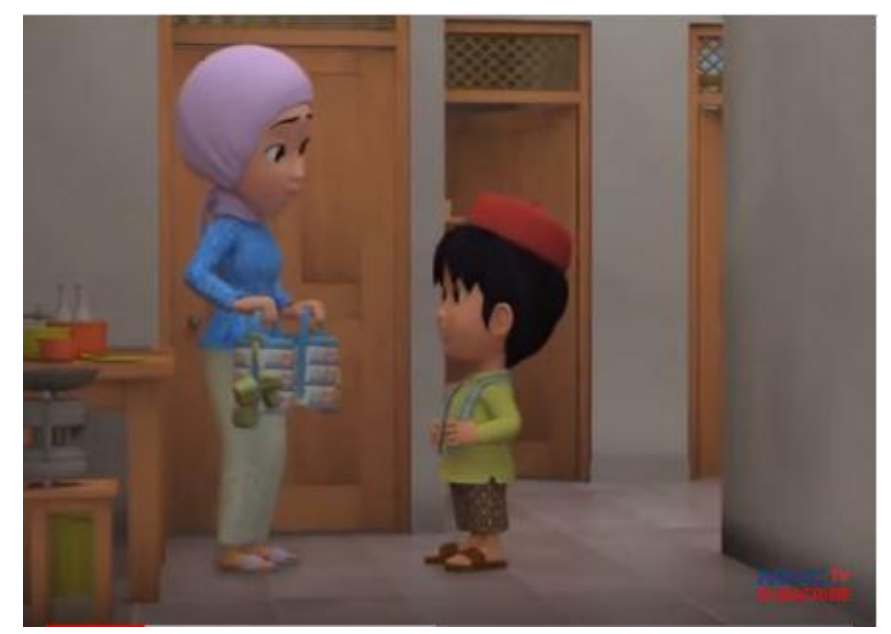

Sumber: MNC Animation 2014

\section{Gambar 1}

Pada gambar 1 dialog yang terjadi antara ibu Entong dan Entong sebagai berikut:

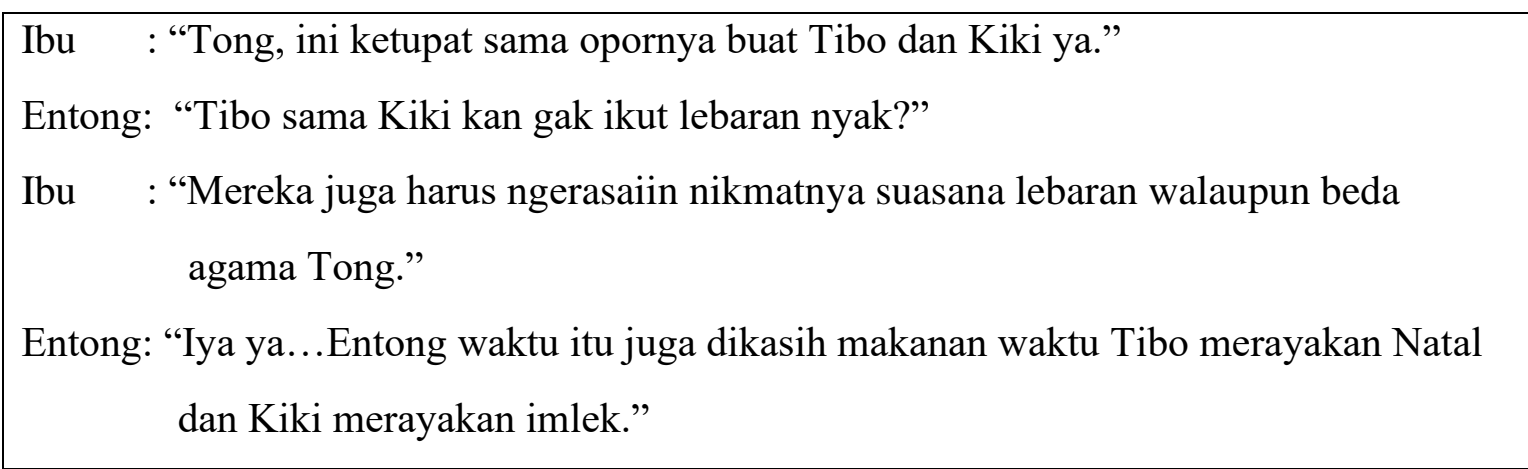

Pada dialog ini, si ibu Entong menjelaskan bahwa Tibo dan Kiki meskipun berbeda agama tapi juga harus ikut merasakan lebaran. Kemudian, si Entong merespon bahwa Tibo merayakan Natal dan Kiki merayakan imlek. Berdasarkan dialog tersebut, adanya penyampaian akan nilai pluralisme yang terjadi antara Entong dan temannya yang tidak merayakan lebaran.

Dialog di atas mengacu pada komponen knowledge (pengetahuan) bahwa perbedaan kebudayaan antara Kiki dan Tibo yang merayakan imlek dan Natal menjadi nilai yang perlu disampaikan kepada anak-anak sehingga ketika mereka berinteraksi dengan yang berbeda kebudayaan, mereka tidak akan merasa aneh, dan mereka juga belajar untuk menghargai. Rocmah (2019:1) menyatakan bahwa sekolah wajib menanamkan nilai-nilai toleransi dan kebersamaan dalam meminimalisir perilaku sosial yang sering kali terjadi di kalangan anak usia dini seperti saling mengejek mengenai warna kulit, jenis rambut, status sosial, dan sebagainya 
Selain itu, adanya mindfulness (kesadaran) yang mengungkapkan bahwa adanya kesadaran yang dimilikki Entong dan teman-temannya, yang dipresentasikan pada saat: Tibo dan Kiki yang tidak merayakan lebaran tapi, mereka berdua juga harus merasakan suasana lebaran. Kemudian, Entong yang tidak merayakan Natal dan imlek tapi, juga ikut merasakan suasana Natal dan Imlek, yaitu dengan diberikan makanan oleh kedua temannya. Dalam hasil penelitian yang dilakukan oleh menunjukkan bahwa Rofi'ah (2013:9) pada generasi tiga berbekalkan pengetahuan budaya kedua belah pihak dan mindful reframing, hubungan relasi sebagai identitas diri ditunjukan dengan persahabatan antar suku, yaitu adanya kedekatan satu orang Sunda dengan satu suku Madura. Pertemanan yang terjalin dengan saling menginap dirumah temannya, bergerombol baik untuk berdiskusi berbagai kegiatan masjid dan bisnis anak muda di arena-arena interaksi bersama, maupun untuk nongkrong dan minum kopi semata.

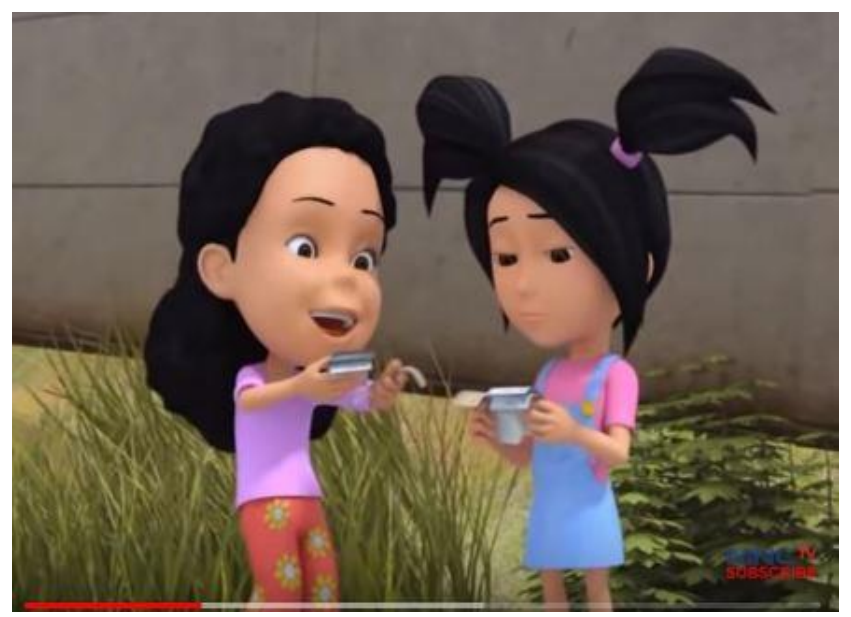

Sumber: MNC Animation 2014

Gambar 2

\begin{tabular}{|c|c|}
\hline Siti & : “Asik, angpao ku dapat banyak." \\
\hline Ipeh & : "Ya... aku baru sedikit keliling lagi yuk." \\
\hline \multicolumn{2}{|c|}{ Siti \& Ipeh : "Kamu darimana Tong" } \\
\hline Entong & : "Habis nganterin ketupat sm opor buat Kiki dan Tibo." \\
\hline Ipeh & : "Ikut kita yuk keliling minta maaf sama minta angpao." \\
\hline Entong & $\begin{array}{l}\text { : "Kata Ustad Somat kalau kita maaf-maafan, kita bisa suci lagi lho kayak } \\
\text { orang baru lahir." }\end{array}$ \\
\hline
\end{tabular}

Dialog dalam gambar 2, juga menyampaikan penggunaan kata angpao. Pada tahap ini, ingin memberikan informasi bahwa istilah angpao yang biasa digunakan oleh etnis Tionghoa pada saat hari raya imlek, juga dipakai pada saat hari raya lebaran. Aliyanto \& Sari (2019: 4) memberikan kajian bahwa Ang pao merupakan amplop merah tidak hanya 
diberikan pada saat hari raya Imlek saja tetapi pada juga diberikan pada saat acara Shang Jit (lamaran). Kemudian, adanya kesadaran dalam memahami (mindfulness) bahwa meskipun angpao sebagai bagian dari tradisi Etnis Tionghoa, itu bukan merupakan hal yang aneh jika istilah tersebut juga digunakan pada saat hari raya lebaran. Terakhir, mengacu pada tahap skill (kemampuan), yaitu penggunaan kata angpao yang diucapkan oleh teman-teman Entong yang merayakan lebaran.
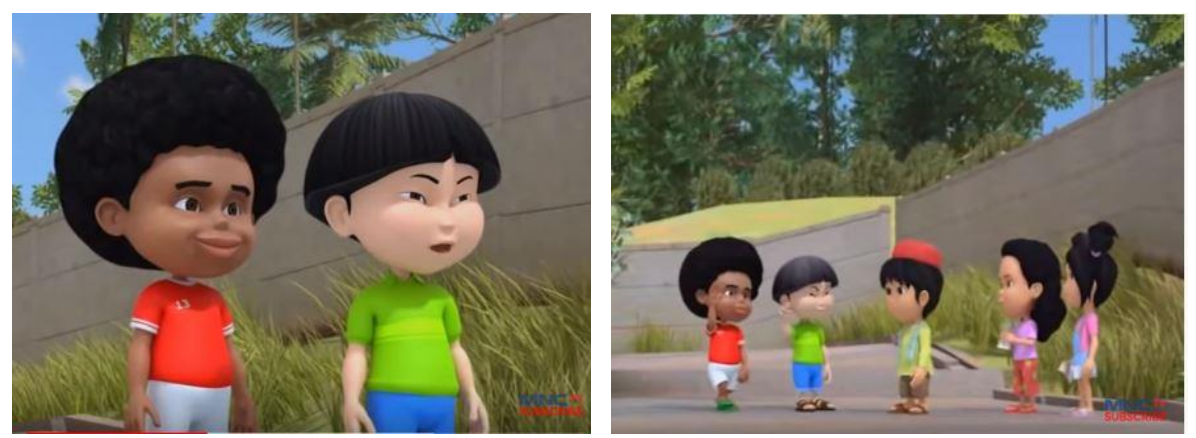

Sumber: MNC animation 2014

\section{Gambar 3}

Kiki: "Tong, ketupat dan opor buatan enyak kamu enak. Makasih ya."

Tibo: "Iya kakak. boleh nambah tidak".

Entong: "Boleh tapi entar ya... lebaran tahun depan hehehhe."

Dalam dialogue gambar 3, memaparkan komponen knowledge, yaitu rasa saling menghargai melalui ucapan terima kasih yang dilontarkan oleh Tibo dan Kiki. Kemudian, penggunaan kata opor dan ketupat yang diucapkan oleh Kiki. Tyas (2017:7) mendefiniskan bahwa ketupat termasuk dalam jenis kuliner nasional khas Indonesia yang menjadi suatu representasi budaya lokal Indonesia, dan selalu disajikan pada saat lebaran atau Hari Raya Idul Fitri. Selain itu, ada juga penggunaan kata enyak yang digunakan oleh Kiki, dan kata kakak yang diucapkan oleh Tibo.

Kemudian, adanya kesadaran (mindfulness) bahwa panggilan ibu antara etnis Tionghoa dan budaya betawi ternyata berbeda. Dalam hal ini, Kiki menyadari perbedaan sapaan di antara budaya yang berbeda. Selanjutnya, si Kiki berada pada komponen kemampuan (skill) karena menggunakan kata enyak yang merupakan kata bahasa betawi untuk ibunya Entong. Pada tahap ini, Kiki yang sebagai etnis Tionghoa paham bahwa dalam budaya betawi, ia harus menggunakan kata enyak sebagai panggilan ibu teman-temannya. Seperti yang dipaparkan dalam Setiawati (2018: 9) bahwa kata sapaan dalam bahasa betawi yang tidak terdapat dalam bahasa Indonesia, yaitu Baba/ Babeh, Enyak/ emak, Abang, Empo, Entong, Eneng, Kumpi, Engkong/ Baba, Nyak Tua/ Uwa/ Nyaik. 


\section{Episode Si Entong “Liang Liong”}

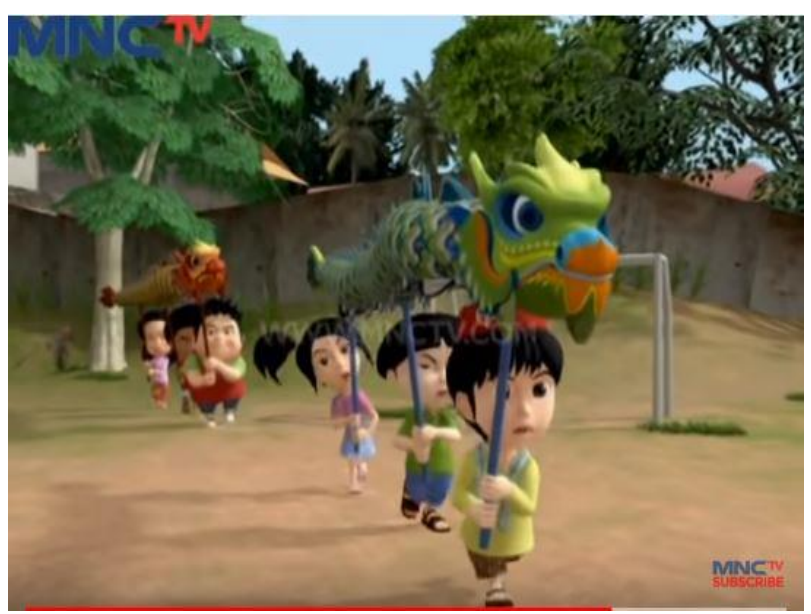

Sumber: MNC animation 2014

\section{Gambar 4}

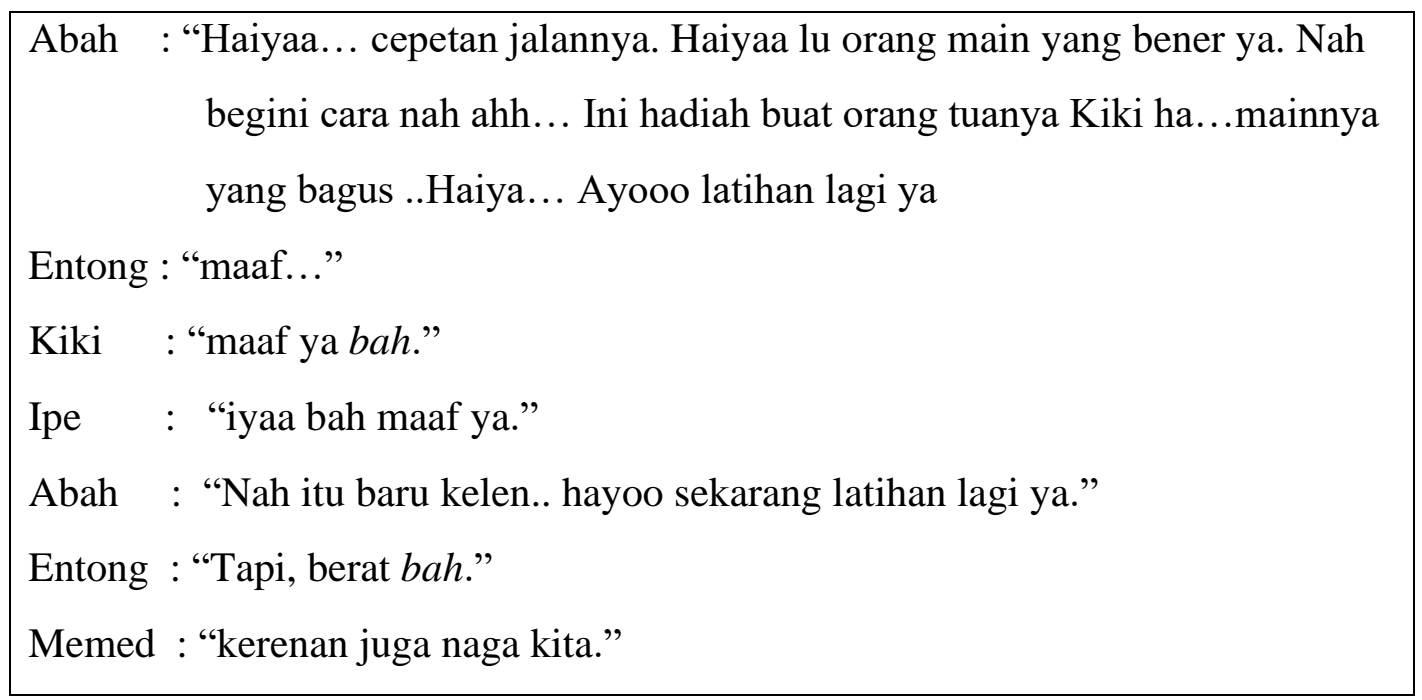

Dalam dialog di atas, penulis skenario ingin memperkenalkan budaya Etnis Tionghoa melalui episode Liang Long atau Tarian Naga. Tahap ini sebagai bagian dari komponen pengetahuan (knowledge) yang ingin menyampaikan bahwa Liang Long merupakan salah satu kesenian yang ada di budaya etnis Tionghoa. Cahyani (2016:3) menjelaskan LiangLiong atau tari naga ( wu long) berasal dari zaman Dinasti Han, yang dimainkan oleh orangorang Tionghoa karena mereka memiliki kepercayaan dan rasa hormat yang besar terhadap naga. Selain itu, dalam episode ini menampilkan juga ciri khas Etnis Tionghoa melalui cara berbicaranya. Rachman (2014:3) menjelaskan bahwa secara perilaku dan keyakinan etnis Tionghoa memang memiliki karakteristik sendiri, khususnya saat merayakan hari keagamaan, dan ciri-ciri fisik, misalnya bermata sipit dan kulit putih.

Selain itu, adanya pengenalan kata $a b a h$, sapaan yang biasanya digunakan pada masyarakat betawi tapi, juga digunakan bagi etnis Tionghoa. Bahtiar (2018:7) memaparkan bahwa identitas Betawi lainnya ditandai dalam istilah sapaan kekerabatan, seperti bapak, 
abah, babeh, abang, mamang, empok, neng, nok, dan lain-lain. Penggunaan kata abah yang ditujukan kepada etnis Tionghoa menjadi sesuatu yang unik, dan hal ini mengindikasikan bahwa istilah tersebut juga bisa digunakan oleh etnis dari budaya lain. Padahal panggilan untuk etnis Tionghoa mengacu pada kata berbahasa mandarin seperti yang diungkapkan oleh Susanto (2017:11) dimana dalam film "Ngenest" penggambaran budaya Etnis Tionghoa dalam segi banyak didominasi oleh kata panggilan berbahasa Mandarin, seperti kata Kokoh, Engkoh, Engkong, Cici, Tacik, Kyu Kyu, Encek, hingga Kung Kung.

Selanjutnya, mindfulness sebagai sebuah kesadaran bahwa etnis Tionghoa memiliki budaya dan karakteristik sendiri sehingga adanya skill (kemampuan) dari Entong dan temantemannya untuk menerima tarian naga dan bahkan ikut berlatih bersama Kiki dengan dipimpin oleh abah. Permatasari (2015:3) menuturkan bahwa mahasiwa yang memiliki kesadaran multikulturalisme akan memiliki kesadaran diri yang tinggi sehinga mereka mampu menjalin persahabatan baru dengan orang lain, mengembangkan keterampilan interpersonal yang baik, dan menghadapai stereotype dan prasangka terhadap orang lain.

Falah dan Suharjianto (2009: 5) juga memaparkan bahwa kesenian Liong dan Barongsai sebagai ruang bagi para anggotanya yang berbeda etnis untuk saling mengenal dan memahami satu terhadap yang lain, dengan begitu, secara sosial dan spiritual mereka mampu memahami makna sesungguhnya dari hidup bersama dengan orang yang memiliki perbedaan kultur. Pada tahap skill (kemampuan) ini, tarian naga bukan lagi menjadi sebuah tarian khusus untuk etnis Tionghoa saja tapi juga bisa untuk berbagai kalangan dari latar belakang yang berbeda.

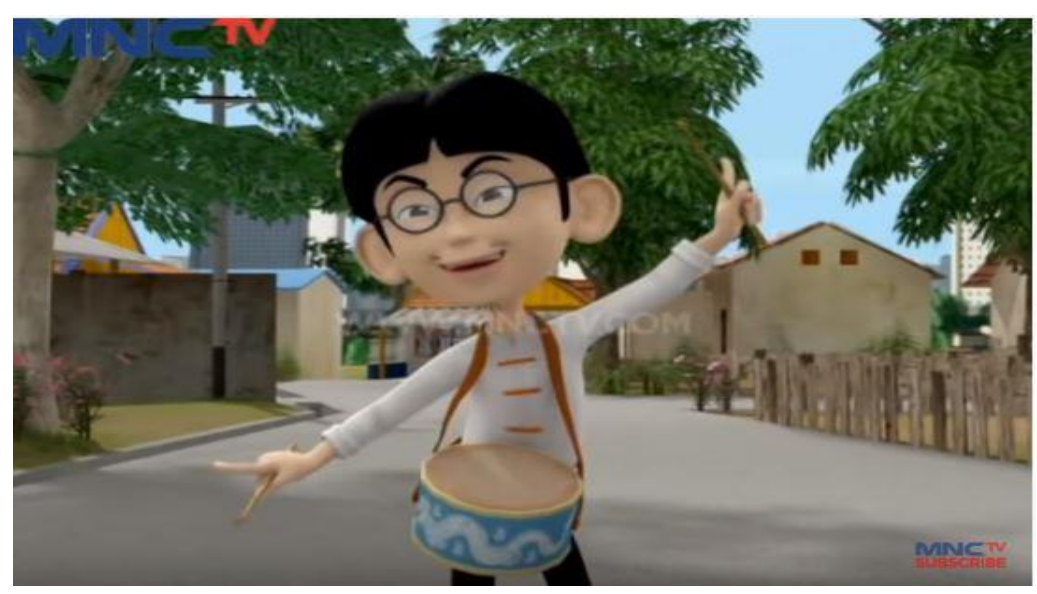

Sumber: MNC animation 2016

Gambar 5

Abah: "Haiyaa setop setoppp weiii nanti liong oee rusak. Haduh lu orang bagaimana sh. Nanti liong oe rusak aduh bagaimana sh"

Entong: "Temen-temen kita harus selamatkan liong ini." Ayoo kabur...

Penggunaan kata Liong yang mengacu pada kata naga sebelumnya juga dipresentasikan dalam episode ini. Penulis skenario ingin menyampaikan bahwa kata lain 
naga dalam bahasa mandarinnya itu adalah liong. Sebuah tahap knowledge (pengetahuan) bahwa etnis Tionghoa biasa menyebut naga sebagai Liong. Kemudian, adanya mindfulness (kesadaran) dari Entong yang mau menerima bahwa istilah lain dari naga adalah Liong. Terakhir, Entong yang awalnya menggunakan kata naga, menggantinya dengan kata liong. Hal ini menunjukkan bahwa Entong sebagai anak dari budaya betawi mampu melakukan negosiasi identitas di tengah lingkungan teman-temannya yang berbeda budaya. Heryadi dan Silvana (2013:8) memaparkan bahwa seseorang yang hidup di masyarakat yang berbeda mempunyai tantangan baik dari bahasa, sikap masyarakat, sistem kepercayaan serta budaya yang berbeda dengan lingkungan sebelumnya. Oleh karena itu, perlu adanya sikap saling menghargai budaya antar warga masyarakat agar dapat beradaptasi dan hidup di masyarakat yang beragam etnis.

Tahap pengetahuan (knowledge) juga disampaikan melalui logat bahas yang digunakan oleh abah untuk menunjukkan identitasnya sebagai etnis Tionghoa. Pengenalan akan logat etnis Tionghoa mengajarakan kepada anak-anak bahwa setiap etnis mempunyai logat yang berbeda-beda. Prajnagaja (2010:10) dalam jurnalnya mengungkapkan beberapa informan sepakat bahwa orang Tionghoa saat berbicara memiliki logat yang sangat jelas sekali. Nurhayati (2011: 17) menambahkan bahwa peran sekolah terutama guru-guru di dalam kelas yang terdiri dari anak-anak adalah dengan membuat peraturan tentang tidak adanya diskriminasi bahasa, seperti menertawakan, mengejek, menghina bahasa orang lain (termasuk di dalamnya logat bahasa, aksen dan dialek) di sekolah tersebut dan dan menghargai keberagaman bahasa. Pada tahap ini, bisa disimpulkan bahwa memperkenalkan logat bahasa etnis lain menjadi hal yang penting agar anak-anak dapat belajar menghargai sebuah perbedaa, terutama dalam sebuah logat bahasa.

Kemudian, pada tahap mindfulness (kesadaran) terlihat bahwa logat bahasa etnis Tionghoa tetap dipertahankan sebagai identitas dari etnis Tionghoa, dan hanya digunakan pada etnis Tionghoa saja. Terakhir pada tahap skill (kemampuan), si Entong dan temantemannya menghargai logat bahasa dari si abah yang merupakan etnis Tionghoa. Rahman dan Jafar (2017:3) memaparkan bahwa pemahaman lintas kultur sebagai pengakuan dasar terhadap martabat dan hak manusia dalam memegang kepecayaan dan nilai-nilai yang membedakan dengan orang lain dapat mendorong sikap empati, kekerabatan, dan menerima perbedaan kepentingan dan kesenangan sebagai upaya untuk munculnya sikap inferior terhadap kelompok lain.

\section{PENUTUP}

Keberagaman budaya bangsa Indonesia yang telah dipersatukan melalui Bhinneka Tunggal Ika perlu terus diperkenalkan dari generasi ke generasi. Film animasi Si Entong meskipun dengan durasi yang singkat melalui dua episodenya, yaitu "Maaf lahir batin ya" dan "Liang Liong" telah merefleksikan pluralism melalui interaksi yang dilakukan oleh Entong dengan temannya yang berbeda suku dan budaya melalui komponen pengetahuan (knowledge), mindfulness (kesadaran), dan skill (kemampuan). Pada tahap knowledge, memperlihatkan kepada anak-anak bahwa setiap etnis memiliki kebudayaannya masing- 
masing, seperti perayaan Natal, Imlek, dan Lebaran. Hal ini menjadi pembekalan bagi mereka sehingga tidak merasa asing dan aneh jika bertemu dengan lingkungan yang berbeda budaya. Selanjutnya, pada tahap mindfulness mulai adanya kesadaran terhadap budaya yang berbeda, yaitu bahwa ketika ada teman yang merayakan Natal dan imlek, mereka juga harus mengajak mereka merasakan suasana lebaran dan sebaliknya. Terakhir, adanya skill yang bisa menerima perbedaan yang ada dan menghargai budaya teman-temannya, yaitu penggunakan panggilan enyak dan abah dalam bahasa betawi yang diungkapkan oleh etnis Tionghoa dalam cerita tersebut, dan bermain Liang Liong yang merupakan tarian naga etnis Tionghoa. Melalui tahap-tahap negosiasi identitas yang ditampilkan dalam film Si Entong dapat disimpulkan bahwa nilai pluralisme telah tersampaikan kepada anak-anak, yaitu adanya perbedaan agama, logat bahasa, bahasa, dan kesenian tidak menghalangi mereka untuk saling berinteraksi satu sama lain tapi, mereka dapat bersahabat dan saling menghargai dalam perbedaan-perbedaan yang ada.

Harapannya dari penelitian ini, perlu adanya penelitian lebih lanjut lagi serta penggunaan metode lain dalam menelaah nilai-nilai pluralism yang terkandung dalam sebuah film animasi anak-anak. Selain itu, diharapakan adanya perhatian khusus terhadap animasi kartun anak-anak lokal dalam memperkenalkan identitas budaya Indonesia kepada generasi penerus. Penelitian ini dapat dijadikan rujukan dalam menyampaikan nilai-nilai pluralisme melalui fillm kartun anak-anak.

\section{REFERENSI}

Aliyanto, Deky. N, dan Sinta, Kumala.S. (2019). Makna Warna Merah Dalam Tradisi Etnis Tionghoa Sebagai Jembatan Komunikasi Untuk Meperkenalkan Makna Darah Yesus: Jurnal Gamaliel. http://jurnal.stt-gamaliel.ac.id/index.php/gamaliel/article/view/39

Arsita, Melvi. (2014). Pengaruh Tayangan Film Kartun Terhadap Pola Tingkah Laku Anak Usia Sekolah Dasar: Jurnal Kultur Demokrasi, 2(7). http://jurnal.fkip.unila.ac.id/index.php/JKD/article/view/4730/3010

Bahtiar, Ahmad. (2018). Sastra Warna Lokal Betawi Sebagai Bahan Pembelajaran Bahasa Indonesia Untuk Penutur Asing (BIPA): Jurnal Pemikiran Alternatif Kependidikan, 23 (1). http://ejournal.iainpurwokerto.ac.id/index.php/insania/article/view/2008

Basseng. (2019). Modul Pelatihan Dasar Calon PNS: Wawasan Kebangsaan dan Nilai Bela Negara, 2019. https://www.coursehero.com/file/34893587/Modul-8-Kesiapsiagaan-Bela-Negarapdf/

Boer, R. F., \& Lesmana, D. (2018). Eksplorasi Faktor Beliefs Dan Attitudes: Kajian Terhadap Social Judgement Theory Di Era Media Digital. Bricolage: Jurnal Magister Ilmu Komunikasi, 4(01), 51-63. https://doi.org/10.30813/bricolage.v4i01.1067 
Cahyani, Mareta.F. (2016). Karya MusiLong Huang" Dalam Tinjauan Karakteristik Melodi dan Harmoni: Jurnal Mahasiswa Unesa. https://docplayer.info/41243228-Abstrak-karya-musik-long-huang-dalam-tinjauankarakteristik-melodi-dan-hamoni.html

Fajar, Yusri. (2011). Negosiasi Identitas Pribumi dan Belanda dalam Sastra Poskolonial Indonesia Kontemporer: Jurnal University of Jember, 1(2). https://jurnal.unej.ac.id/index.php/LIT/article/view/5595

Falah, Fajarul, dan Suharjianto. (2009). Peran Kesenian Liong dan Barongsai Sebagai Sarana Assimilasi Antara Etnis Tionghoa dan Etnis Jawa (Studi kasus perkumpulan Liong dan Barongsai Tripusaka MAKIN Solo): Publikasi Ilmiah. 4(1). https://publikasiilmiah.ums.ac.id/handle/11617/1008

Fensi, F. (2018). FENOMENA HOAX : Tantangan terhadap Idealisme Media \& Etika

Bermedia. Bricolage : Jurnal Magister Ilmu Komunikasi, 4(2), 1-16.

https://doi.org/http://dx.doi.org/10.30813/bricolage

Sundari, Fitri. (2017). Penerapan Program FOS (Folktale Speaking) sebagai Pembentuk Karakter Anak usia Dini: Jurnal Pendidikan Ilmu-ilmu Sosial. 9 (1).

https://jurnal.unimed.ac.id/2012/index.php/jupiis/article/view/6423

Hadiwidjaja, Joshua Xavier. (2017). Perancangan Video Edukasi Kesenian Jawa Karawitan

Dalam Bentuk Animasi Bagi Anak Usia 5-6 Tahun: Jurnal DKV Adiwarna,

Universitas Kristen Petra.1.

http://publication.petra.ac.id/index.php/dkv/article/view/5563

Hamdun, Dudung. (2017). Pendidikan Keluarga Sebagai Manifestasi Basic Nilai-Nilai Pluralisme di Dukuh Kalipuru Kendal: Jurnal Pendidikan Dasar Islam. 9 (2). https://media.neliti.com/media/publications/284637-pendidikan-keluarga-sebagaimanifestasi-4d58d335.pdf

Haryono, C. G. (2017). Praktek Produksi Hegemoni Militer Melalui Film "Jenderal

Soedirman.” Bricolage: Jurnal Magister Ilmu Komunikasi, 3(01), 30-42.

https://doi.org/10.30813/bricolage.v3i01.844

Heryadi, Hedi, dan Hana, Silvana. (2013). Komunikasi Antarbudaya Dalam Masyarakat Multikultural: Jurnal Kajian Komunikasi. 1 (1) http://jurnal.unpad.ac.id/jkk/article/view/6034

Hidayat, Dasrun. (2014). Social and Cultural Identity Pendekatan Face Negotation Theory dan Public Relations Multikulturalism Negara Jerman-China dan Indonesia:

Jurnal Aspikom. 2(2). http://jurnalaspikom.org/index.php/aspikom/article/view/64

Ikmal. (2015). Internalisasi Nilai-Nilai Pluralisme dalam Pendidikan Islam: Jurnal Ilmiah Qura. $9(1)$.

http://journal.iain-manado.ac.id/index.php/JII/article/view/596 
Kohibacher, Florian. (2006). Forum: Qualitative Social Research: The use of Qualitative Content Analysis in Case Study Research. 7(1). http://www.qualitative-research.net/index.php/fqs/article/view/75

Kristiyono, J., \& Sirikit, H. (2019). MENELISIK SIASAT CERITA DIGITAL REALITY PADA FILM READY PLAYER ONE? Bricolage : Jurnal Magister Ilmu Komunikasi, 5(2), 159-176. Retrieved from https://journal.ubm.ac.id/index.php/bricolage/article/view/1657/1395

\section{Marta, R. F. (2017). REFLEKSI HIBRIDITAS BUDAYA DALAM PANCASILA PADA REALITAS DAN MEDIA SEBAGAI IDENTITAS BANGSA. Bricolage : Jurnal Magister Ilmu Komunikasi, 3(1), 1-12.}

Marta, Rustono. F, dan Jean, Sierjames. (2018). Identifikasi Nilai Kemajemukan Indonesia Sebagai Identitas Bangsa dalam Iklan Mixagrip Versi Keragaman Budaya: Jurnal Kajian Komunikasi, 6 (1).

http://jurnal.unpad.ac.id/jkk/article/view/15416

Muslim. (2018). Varian-Varian Paradigma, Pendekatan, Metode, dan Jenis Penelitian Dalam Ilmu Komunikasi: Media, Sastra, dan Budaya Wahana, 1(10). https://journal.unpak.ac.id/index.php/wahana/article/view/654

Mushodiq, Muhamad.A. (2017). Teori Identitas dalam Pluralisme dan Toleransi Beragama (Studi di Desa Jrahi, Gunungwungkal, Pati, Jawa Tengah): Jurnal Kajian Agama, Sosial, dan Budaya, 2 (2). https://journal.iaimnumetrolampung.ac.id/index.php/jf/article/view/145

Nahak, M. I..(2019). Upaya Melestarikan Budaya Indonesia di Era Globalisasi: Effort to preserve Indonesian Culture in the Era of Globalization Hildigardis: Jurnal Sosilogi Nusantara, 5 (1).

https://ejournal.unib.ac.id/index.php/jsn/article/view/7669

Nurhayati, Anin. (2011). Menggagas Pendidikan Multikultur di Indonesia: Sekolah Tinggi Agama Islam (STAIN) Tulungagung. http://docplayer.info/36922740-Menggagas-pendidikan-multikultur-di-indonesiaanin-nurhayati-jurusan-tarbiyah-sekolah-tinggi-agama-islam-stain-tulungagung.html

Octaviani, Laila. (2013) Pandatara Dan Jarlatsuh Model Pendidikan Multikultural di SMA Taruna Nusantara Magelang: International Journal of Indonesian Society and Culture, 5 https://journal.unnes.ac.id/nju/index.php/komunitas/article/view/2383

Phillip, Mayring. (2014). Qualitative content analysis: theoretical foundation, basic procedures and software solution, 2014.

https://www.ssoar.info > ssoar > handle > document 
Permatasari, Devi, dkk. (2015). Tingkat Kesadaran Multikultural dan Urgensinya dalam Bimbingan dan Konseling: Jurnal Konseling Indonesia, 3 (1). https://docplayer.info/48612399-Kesadaran-multikultural-dan-urgensinya-dalambimbingan-dan-konseling.html

Prajnagaja, Ekasiv.(2016). Komunikasi Antar Budaya Mahasiswa Etnis Tionghoa Dengan Mahasiswa Pribumi di Fakultas Eknomi Universitas Riau: Jurnal Online Mahasiswa Fakultas Ilmu Sosial dan Ilmu Politik, 3 (2). https://jom.unri.ac.id/index.php/JOMFSIP/article/view/9378

Rachman, Rio.F. (2014). Representasi Diskriminasi Etnis Tionghoa Dalam Film Babi Buta yang Ingin Terbang: Kanal, 2 http://ojs.umsida.ac.id/index.php/kanal/article/view/299

Rahman, Qashas, dan Muhammad, Basri. J. (2017) Model Revolusi Mental Berbasis pendidikan Multikultur dalam Perkuliahan Intercultural Communication: Universitas Negeri Makasar. https://ojs.unm.ac.id/semnaslemlit/article/view/4013

Rofi'ah. (2013). Efektivitas Komunikasi Antarbudaya (Kasus Manajemen Konflik Antara Suku Sunda Dan Suku Madura Di Kelurahan Kebon Kelapa-Bogor): Universitas Ibn Khaldun Bogor. https://docplayer.info/30765808-Efektivitas-komunikasi-antarbudaya-suku-sundadan-suku-madura-kasus-manajemen-konflik-di-kelurahan-kebon-kelapa-kecamatanbogor-tengah-kota-bogor.html

Rohmawati, Yuning.I. (2017). Negosiasi Identitas Sosial Etnis Jawa di Kota Metropolitan: Sebuah Studi Fenomenologi pada masyarakat Kampung Jawa. Mediakom, 1(2). https://ejournal.gunadarma.ac.id/index.php/mediakom/article/view/1887

Santalia, Ido. (2015). K.H. Abdurrahman Wahid: agama dan negara pluralism, demokratisasi, dan pribumisasi, 1(1). http://journal.uin-alauddin.ac.id/index.php/adyan/article/view/1340

Setiawati, Sulis. (2018). Perbandingan Kata Sapaan Dalam Bahasa Indonesia dan Bahasa Betawi Serta Implikasinya Pada Pembelajaran Bahasa Indonesia: Universitas Indraprasta PGRI Jakarta, 1 http://proceeding.unindra.ac.id/index.php/dispanas2018/article/view/165

Susilo, Nico Setiawan. (2013) Identity Management Primary Relationship Berbudaya Jawadan Toraja Identity: Jurnal e-Komunikasi, http://publication.petra.ac.id/index.php/ilmu-komunikasi/article/view/93

Susanto, Irene. (2017). Penggambaran Budaya Etnis Tionghoa dalam Film "Ngenest": Prodi Ilmu Universitas Kristen Petra Surabaya: Jurnal E-Komunikasi 5 (1). http://publication.petra.ac.id/index.php/ilmu-komunikasi/article/view/6141 
Sundari, Fitri. (2017). Penerapan Program FOS (Folktale Speaking) sebagai Pembentuk Karakter Anak Usia Dini: Jurnal Pendidikan Ilmu-ilmu Sosial, 9 (1). https://jurnal.unimed.ac.id/2012/index.php/jupiis/article/view/6423

Setiawan, Budi. (2016). Kreativitas dan Inovasi Seni Pertunjukan Ssebagai Jembatan Membangun Multikultur: Studi kasus Masyarakat Kota Mataram: Jurnal Penelitian Sejarah dan Nilai Tradisional, 23 https://jurnalbpnbbali.kemdikbud.go.id/jurnal/index.php/penelitian/article/view/1

Suryandi, Nikmah. (2017). Eksistensi Identitas Kultural di Tengah Masyarakat Multikultural dan Desakan Budaya Global.

https://www.researchgate.net/publication/316264818_EKSISTENSI_IDENTITAS_K ULTURAL_DI_TENGAH_MASYARAKAT_MULTIKULTUR_DAN_DESAKAN

- $\quad$ BUDAYA_GLOBAL

Tyas, Agnes Siwi Purwaning. (2017). Identifikasi Kuliner Lokal Indonesia dalam Pembelajaran Bahasa Inggris: Jurnal Parwisata Terapan, 1(1). https://jurnal.ugm.ac.id/jpt/article/view/24970

Yanti, Fitri. (2011). Komunikasi Sosial Dalam Membangun Komunikasi Umat (Kajian Makna Tradisi IED (Lebaran) Pada Masyarakat Muslim Di Bandar Lampung): Jurnal Komunika, 2 (1). http://ejournal.radenintan.ac.id/index.php/komunika/article/view/4752

Yahya, Nurul.A, dan Rahardjo, Turnomo. (2018). Negosiasi Identitas Mahasiswa Papua Dengan Host Culture di Kota Semarang Nurul Athira, 6 (1). https://ejournal3.undip.ac.id/index.php/interaksi-online/article/view/19113 